Jurnal Pemberdayaan: Publikasi Hasil Pengabdian kepada Masyarakat

Vol. 2, No. 3, Desember 2018, Hal. 381-386

ISSN: 2088 4559; e-ISSN: XXXX-XXXX

DOI:

\title{
PELATIHAN PENYIAPAN KEHIDUPAN SEHAT BAGI PETUGAS DAN REMAJA DI PANTI ASUHAN YATIM PUTRI AISYIYAH SERANGAN YOGYAKARTA
}

\author{
Sitti Nur Djannah ${ }^{1}$, Nurul Qomariyah ${ }^{2}$ \\ Universitas Ahmad Dahlan, Yogyakarta ${ }^{1,2}$ \\ sitti.nurdjannah@ikm.uad.ac.id ${ }^{1}$
}

\begin{abstract}
ABSTRAK
Fenomena permasalahan remaja saat ini menjadi perhatian yang perlu diperhatikan dan ditindaklanjuti dengan bijaksana, agar remaja sebagai penerus bangsa dapat diandalkan kemampuannya untuk bangsa Indonesia. Sebagai penerus bangsa, remaja diharapkan sehat. Kesehatan yang diharapkan pada remaja adalah sehat menyeluruh, yaitu sehat secara fisik, mental, sosial, religi dan produktif. Untuk ini dibutuhkan informasi dan pelatihan yang akurat. Untuk sehat secara fisik, perlu pemahaman remaja pentingnya aktivitas fisik yang dapat membuat badan sehat, salah satunya adalah kesadaran untuk menyenangi olah raga. Metode yang digunakan adalah pelatihan dan praktek penyiapan kehidupan sehat bagi Petugas dan remaja di Panti Asuhan Yatim Putri Aisyiyah Serangan Yogyakarta. Hasil dari kegiatan diperoleh bahwa ada peningkatan pemahaman petugas dan remaja di lokasi penelitian
\end{abstract}

Kata kunci : pelatihan, sehat, Panti asuhan, Remaja

\begin{abstract}
The current phenomenon of adolescent problems is a concern that needs to be considered and acted on wisely, so that adolescents as the nation's successors can be relied upon for their ability in the Indonesian nation. As the nation's successor, teenagers are expected to be healthy. Health expected in adolescents is a comprehensive health, which is healthy physically, mentally, socially, religiously and productively. This requires accurate information and training. To be physically fit, teenagers need to understand the importance of physical activity that can make a healthy body, one of which is awareness to enjoy sports. The method used was training and practice of preparing healthy life for Officers and Adolescents at the Yatim Putri Aisyiyah Asphalt Attack in Yogyakarta. The results of the activities obtained that there was an increase in the understanding of officers and adolescents at that location
\end{abstract}

Keywords: training, health, orphanages, adolescents 


\section{PENDAHULUAN}

Pemahaman remaja akan kesehatan menjadi bekal remaja dalam berperilaku sehat dan bertanggungjawab, namun tidak semua remaja memperoleh informasi yang cukup dan benar tentang kesehatan. Keterbatasan pengetahuan dan pemahaman ini dapat membawa remaja kearah perilaku beresiko. Sehingga menurut para ahli dalam bidang ini memandang perlu akan adanya pengertian, bimbingan dan dukungan dari lingkungan di sekitarnya agar dalam sistem perubahan terjadi pertumbuhan dan perkembangan yang sehat sedemikian rupa sehingga kelak remaja menjadi manusia dewasa yang sehat secara jasmani, rohani dan sosial (Kumalasari dan Adyantoro, 2012). Terutama dalam menghadapi kehidupan berkeluarga yang sehat di masa depan. Remaja yang sehat adalah remaja sehat secara fisik, mental, sosial, religi, yang tidak hanya terbebas dari penyakit dan kecacatan sehingga hidup produktif secara sosial dan ekonomi.

Dengan demikian, dirasakan perlu dilakukan edukasi dalam bentuk pelatihan kepada remaja secara terus menerus untuk meningkatkan pengetahuan, dan menumbuhkan kesadaran pada remaja akan pentingnya menjaga kesehatan secara umum, khususnya kesehatan reproduksi agar terdapat persiapan yang baik dalam menghadapi masa depannya. Salah satu fungsi remaja yaitu remaja telah melakukan persiapan dalam kehidupan berkeluarga yang sehat. Banyak faktor yang diperlukan dalam menumbuhkan remaja yang sehat, salah satunya adalah yang berkenaan tumbuh kembang remaja, baik secara fisik, mental, sosial, dan spiritual.

Dalam kehidupan berkeluarga yang sehat diperlukan fisik yang sehat, demikian juga emosi yang dapat terkendali sehingga sesuai dengan norma yang ada di masyarakat dan keluarga, juga kemampuan sosial seperti kemampuan berintraksi dengan baik dan adanya tujuan hidup untuk mencapai masa depannya, serta spiritual yang baik agar perilaku remaja dalam kehidupan sehari- hari sesuai dengan norma agama.

Untuk mecapai remaja yang sehat, maka akan dilakukan dalam kegiatan pengabdian yaitu pelatihan persiapan kehidupan sehat pada remaja, khususnya pada remaja di Panti asuhan Yatim Putri Aisyiyah Serangan Yogyakarta. Hal ini dilakukan , karena merupakan salah satu kewajiban UAD sebagai salah satu amal usaha muhammadiyah yang juga bermanfaat, khususnya bagi remaja muhammadiyah lainnya, yaitu remaja PCA Kraton, agar remaja mengetahui perilaku yang sehat persiapan pranikah untuk kehidupan keluarga yang bahagia ke depannya. Sehat secara fisik, emosi, intelektual dan spiritual teemasuk bagi Petugas panti, di mana pelatihan ini dapat diteruskan setelah kegiatan pengabdian selesai. 


\section{METODE}

Untuk mencapai tujuan yang diharapkan, metode pelaksanaan kegiatan ini adalah ceramah, diskusi, penayangan film dokumenter dan praktek (Sulaeman, 2016). Ringkasan metode pelaksanaan beserta jam kerja efektif tersaji pada tabel 1.

Tabel 1. Metode, Kegiatan, Pengabdian di Panti Asuhan Yatim Putri Aisyiyah Serangan

\begin{tabular}{|l|l|l|l|l|}
\hline No & Metode & Kegiatan & JKEM & $\begin{array}{l}\text { Jumlah audien } \\
\text { yang terlibat }\end{array}$ \\
\hline 1 & $\begin{array}{l}\text { Pendidikan } \\
\text { masyarakat }\end{array}$ & $\begin{array}{l}\text { Menyelenggarakan } \\
\text { penyuluhan dan } \\
\text { praktek } \\
\text { Kewirausahaan bagi } \\
\text { remaja }\end{array}$ & $1 \times 2$ jam & 29 \\
\hline $\begin{array}{l}\text { Mengadakan } \\
\text { penyuluhan } \\
\text { Kesehatan } \\
\text { Reproduksi Remaja } \\
\text { dengan audiovisual } \\
\text { dan film dokumenter }\end{array}$ & $\begin{array}{l}\text { Menyelenggarakan } \\
\text { pelatihan jam } \\
\text { meningkatkan religi } \\
\text { remaja dengan } \\
\text { mengadakan evaluasi } \\
\text { diri (muhasabah) }\end{array}$ & $1 \times 2$ jam & 29 \\
\hline Praktek & $\begin{array}{l}\text { Pelatihan senam } \\
\text { kebugaran }\end{array}$ & 29 \\
\hline
\end{tabular}

\section{HASIL, PEMBAHASAN DAN DAMPAK}

a) Profil Panti Asuhan Yatim Putri Aisyiyah Serangan Yogyakarta

Panti Asuhan didirikan oleh Pimpinan Pusat Mauhammadiyah pada tahun 1921, yang menyantuni anak-anak yatim, piatu, yatim piatu, dhu'afa baik putra maupun putri. Pada tahun 1928 Panti Asuhan Muhammadiyah dipisah menjadi: Panti Asuhan Yatim Putra Muhammadiyah dan Panti Asuhan Yatim Putri Aisyiyah yang berlokasi di jalan Munir No. 109 Serangan, Kecamatan Ngampilan Kota Yogyakarta.

Tujuan panti adalah mengimplementasikaan nilai-nilai Al-Qur'an dan Sunah Nabi Muhammad SAW, Menjadikan Organisasi Pelayanan Sosial yang tertib, profesional, mandiri 
dan berkemajuan, mempersiapkan kader-kader penerus perjuangan Muhammadiyah dan Aisyiyah, dan mengantarkan generasi bangsa yang cerdas, berakhlaqul karimah menuju kemandirian hidup yang bermartabat dan berkemajuan.

b) Gambaran Pelaksanaan

Gambar aktivitas remaja putri dan petugas Panti Asuhan Yatim Putri Aisyiyah Serangan dalam program pengabdian kepada masyarakat tersaji pada gambar 1 .

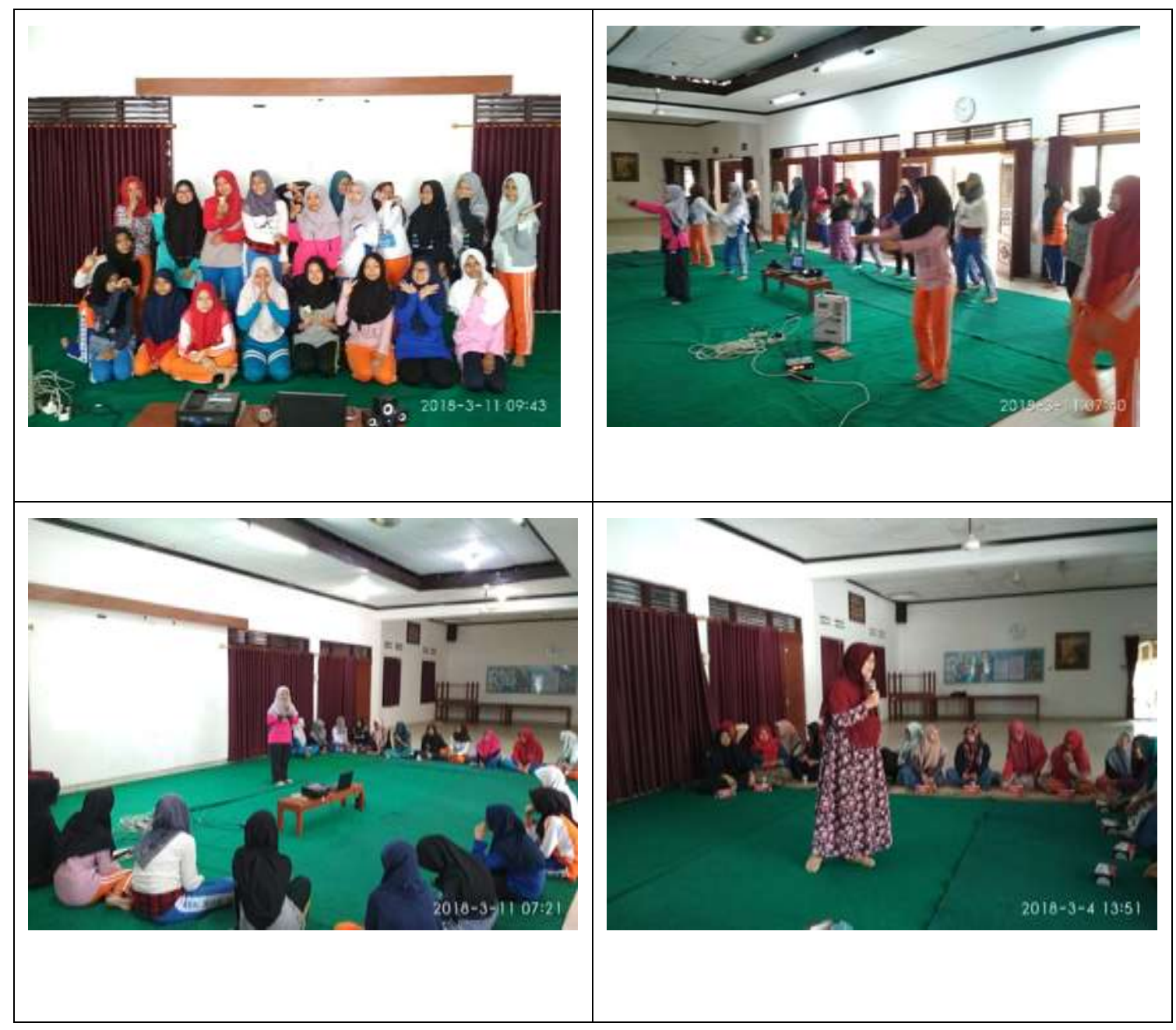

Gambar 1. Aktivitas saat pelatihan kehidupan sehat bagi Petugas dan remaja Panti Asuhan Yatim Putri Aisyiyah Serangan Yogyakarta

Dari gambar terlihat program pengabdian kepada masyarakat di Panti Asuhan yatim Putri Aisyiyah Serangan Yogyakarta dapat terlaksana dengan partisipasi petugas dan remaja yang cukup baik dan terdapat antusias peserta untuk mengikuti semua pelatihan yang telah disediakan.

Dampak dari kegiatan PPM ini adalah : 1) tercipta kesadaran petugas dan remaja panti tentang pentingnya menjaga kesehatan secara menyeluruh ,2) peningkatan perilaku sehat untuk sehat secara fisik dengan kegiatan olah raga, 3) peningkatan perilaku sehat secara 
sosial dengan perilaku sehat dalam pergaulan menghindari dampak seks bebas , 4) peningkatan perilaku sehat secara mental dengan menjaga norma sesuai norma agama, dan 5) peningkatan perilaku sehat secara ekonomi dengan jiwa kewirausahaan remaja.

\section{KESIMPULAN}

Program Pengabdian kepada masyarakat UAD dalam Pelatihan penyiapan kehidupan sehat bagi petugas dan remaja di Panti asuhan Yatim Putri Aisyiyah Seranga Yogyakarta berjalan dengan baik. Terdapat peningkatan pengetahuan dan keterampilan peserta pengabdian.

\section{DAFTAR PUSTAKA}

Kumalasari, Andhyantoro I., 2012, Kesehatan reproduksi untuk mahasiswa kebidanan dan keperawatan, Penerbit Salemba Medika. Jakarta.

Sulaeman, E, S, 2016. Pembelajaran model dan teori perilaku kesehatan konsep dan aplikasi. UNS Press. Surakarta. 
